\title{
Digital citizenship skills among undergraduate students in Malaysia: A preliminary study
}

\author{
Noor Banu Mahadir, Nur Hidayah Baharudin, Nurul Nadia Ibrahim \\ Department of Moral, Civics and Character-Building Studies, Universiti Pendidikan Sultan Idris, Perak, Malaysia
}

\section{Article Info \\ Article history: \\ Received Dec 8, 2020 \\ Revised Jun 13, 2021 \\ Accepted Jul 15, 2021 \\ Keywords: \\ Digital citizenship \\ Online learning \\ Online security \\ Online wellbeing \\ Skills}

\begin{abstract}
The purpose of the study was to examine level of digital citizenship skills among undergraduate students at the Sultan Idris Education University, Perak, Malaysia. The study focused on three sub-variables of digital citizenship skills; online wellbeing, online learning and online safety. The paper present report from a questionnaire conducted on 1000 students from nine different faculties. Items for each variable were constructed based on literature highlights related to digital citizenship framework and through experts' validation. A descriptive statistic was used in determined the level of digital citizenship skills among the undergraduate students. The findings of the study showed that the level of digital citizenship skills of students is at a high level. This study expected to help stakeholders to further emphasize the study of digital citizenship and digital citizenship education in Malaysia in more detail.
\end{abstract}

This is an open access article under the CC BY-SA license.

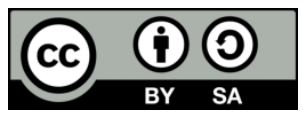

\section{Corresponding Author:}

Noor Banu Mahadir

Department of Moral, Civics and Character-Building Studies, Faculty of Human Sciences

Universiti Pendidikan Sultan Idris

Tanjong Malim, Perak, Malaysia

Email: noor.banu@fsk.upsi.edu.my

\section{INTRODUCTION}

Digital citizenship refers to acceptable norms of behavior related to the use of technology [1]. A collaborative movement, the Digital Literacy and Citizenship Curriculum launched in 2010 by Common Sense Education and the Harvard Graduate School of Education, defines digital citizenship as the responsible use of technology to learn, create, and participate [2]. According to Collier [3], digital citizenship skills formcritical and ethical thinking of what had been seen said and shared when using the medium of communication media technology. Thus, the behavioral norms of a digital citizen are capable of protecting adolescent individuals from engaging in inappropriate behavior, online and offline, such as cybercrime and cyberbullying [4].

Skills are the ability to practice knowledge to act, in turn, demonstrating individual competence [5]. Besides, problem-solving using learned knowledge theories and the ability to communicate on scientific issues [6]. A digital citizen applies to those who have the knowledge and skills to use digital technologies efficiently, connect with others to engage in society, and produce and use digital content. Digital citizenship is about a confident and optimistic engagement with digital technologies [7]. The skills of digital citizens in this study refer to students' skills through aspects of online wellbeing, online learning, and online security.

In Malaysia, CyberSecurity Malaysia had formed to maintain security in cyberspace. Hence, encouraging the sustainability of safe online learning at the national level and social well-being had become the factor in programs such as CyberSAFE focusing on the reach and development of technological capacity [8]. The digital device technology is becoming part of the learning stimulus tool; however, digital devices' 
excessive use can be a threat to digital users. Coupled with inappropriate site content led to a damaging result on physical and emotional well-being [9]. As a result, many parties have realized the importance of digital citizenship education needs to start from the basic level of education [10].

However, the digital literacy concept introduced does not emphasize the importance of online wellbeing, which is the essence of digital citizenship education. This concept serves as a core in digital regulation education and is more accurate when linked to educational or educating elements. Elements of education supposedly educate and cultivate digital citizenship among children, adolescents, and adults to ensure the whole concept of digital citizenship education for deeper understanding. This situation happened because digital citizenship education equips students as responsible users of technology and understands prudent and civilized digital citizens [11].

The use of technology as an aspect of progress is a must. Nevertheless, the insensitivity of using technology well is very contrary to human ethical values. One way to deal with the abuse of technology is to produce more people who have an awareness of being good digital citizens by having a high level of digital citizenship literacy. The literacy of digital citizenship can be achieved through education. Ribble [12] has introduced digital citizenship in schools as a step for students to distinguish the good or bad things that happen when using digital technology. Digital citizenship education can be categorized as a critical medium to help human society understand and address issues contrary to the ethical and professional values of digital citizenship. At the same time, digital citizenship education opens up space in building a literate society with digital technology and information issues. Ribble [12] has identified nine elements that allow students to understand the key to digital citizenship issues.

a. Digital Access: Infrastructure that allows for full participation in the use of electronics in society. We need to realize that not everyone has the same access to technology. Most around the world does not have access or have limited access to computer use and even an internet connection. Therefore, digital citizens need to support equal digital rights.

b. Digital Trading: Electronic trading transactions. The internet has become a world-class shopping mall; digital citizens need to be smart consumers and not fall victim to internet fraud, phishing, or identity theft. They also need to understand that international sources' goods and services can violate the laws and morals of their own country.

c. Digital Communication: Electronic information exchange. There are many options available for instant communication and cooperation using the internet. Digital users who post text, email, or publish content on social media need to be aware of a broad and interconnected digital environment with other digital users. Digital citizens need to make appropriate decisions and responsible choices when they communicate and collaborate on the internet.

d. Digital Literacy: The process of teaching and learning about technology and how to use technology. Learning to use technology has become a habit nowadays; therefore, digital users need to learn how to use technology appropriately. Besides, the concept of education and practice should also be in line with technological innovation. New technology can provide students with a new method of learning and learning media.

e. Digital Ethics: Standards of conduct or procedures for the use of electronics. Digital citizens use technology in an appropriate contextual way. Digital citizens also need to be aware of the implicit and explicit rules in the use of technology.

f. Digital Law: Electronic responsibility for actions and deeds. Digital citizens are aware of the laws related to technology use and can distinguish between legal and illegal use. They comply with copyright laws and other laws that ensure the use of technology is legal and does not infringe/encroach on others' rights.

g. Digital Rights and Responsibilities: The needs and freedoms given to everyone in the digital world. Digital citizens use online materials ethically and agree to live following accepted usage policies or rules and laws.

h. Digital Health: physical and psychological well-being in the world of digital technology. Digital citizens need to be aware of the physical dangers inherent in using technology and any psychological dangers that may be through excessive use or internet addiction.

i. Digital Security: Electronic security as a precaution. Digital citizenship introduces personal information from stolen or hardware and software technology from virus attacks and security hacking.

On the other end of this spectrum, the increasing use and reliance of students on emerging digital technology have led to many violations and abuses. Activities of online bullying [13], [14], sexting [15], [16], texting during lectures [17], and internet plagiarism [18] are popular among college and university students. With current media tools and the Internet performing such a key role in university learning and student life, and with the possibility of exploiting and misusing the steering situation behind the scenes, teaching digital citizenship to students becomes both foundational and non-negotiable [19], [20]. 
The study of digital citizenship is significant to implement because most teenagers in this century do not understand the formation of explicit digital norms and culture. The things that teenagers learn from digital media sites are considered a culture that forces them to agree to participate in various current activities or trends regardless of personal safety factors while online. Besides, the internet as a world without borders is present with good benefits and invites various risks to the current generation [21]. The spirit of digital citizenship needs to be inculcated from the very beginning. Next, the digital citizenship study aims to be a safeguard and security approach while online so that users can interact safely. Digital online security is no longer seen as an option but rather a necessity in digital citizenship.

Previous studies show that the use of the internet has influenced students' lives at the overall level of self-development and changed towards a more digital self-concept [10]. The use of the internet is widely used to meet professional needs and educational development purposes. The development and advancement of information and communication technology have been successfully utilized in meeting needs such as online business, social media, and even one of the facilitators of teaching and learning. However, despite the digital world's progress, which has provided tremendous profits, there is no denying the existence of digital abuse such as online fraud, spreading slander on social media, pornography, and others [22]. Therefore, to overcome the problem, it is necessary to have the skills to be a good digital citizen.

There are several studies on online learning and technology misuse by students, but just a few studies on measuring students' digital citizenship behavior, such as responsible online learning, online safety, and security [23]. Research on digital citizenship is relevant because it helps policymakers and higher learning institutions to consider the trends that exist at a deeper and more substantive level.

According to Yacine and Chien [24], there is still a lack of research on digital citizenship despite the widespread development of the internet and the involvement of online community members. The digital divide can be described based on the definition of the level of digital citizenship. Digital citizenship requires further investigation into innovative educational approaches, pedagogical methods, and routine practices that foster digital literacy. The use of technology in social life has created discomfort and problems that are still difficult to understand from an academic and policy perspective. Therefore, the motivation to analyze the level of skills towards digital citizenship needs to be emphasized.

The literacy skills of digital citizenship include knowledge and attitudes towards the application of the use of digital technology. A study by Mossberger, Tolbert, and Hamilton [25] show that there is a strong relationship between the various forms of internet access such as the use of modems, smartphones, mobile phones and others on the ability for digital citizenship covering aspects of skills and online activities. Mobile phones are the most popular digital tools for internet connection before the use of smartphones and other digital devices.

Digital citizens have contributed to the digital environment due to the advantage of opportunities from information and communication technology. An effective digital environment can be created by using the information and communication technology skills of digital citizens through the principles of ethics, law, security, responsibility and appropriate means [26], [27]. Bennett [28] explains that modern attitudes such as the tendency towards advanced tools of digital users personally and socially in cyberspace form digital citizens who play a role in shaping a safe digital community and environment. Digital citizenship can nurture, educate, and teach individuals to be aware of the dangers posed by the online environment and educate digital users to use digital technologies and platforms consciously and adequately based on ethical and global principles [26], [29]. In establishing a secure community and a safe environment, it is important to determine the level of digital citizenship of students in terms of personal and social development in cyberspace [30].

A study by Elcicek, Erdemci, and Karal [26] suggested that the level of digital citizenship of students in Turkey in terms of online technology skills and digital platform benefits properly and consciously by the respondents involved in this study. In comparison, the ethical and health aspects of digital among consumers seen to be undervalued compared to attention in terms of access, communication, literacy and security. Personal safety skills, while online, are a critical aspect. The safety of using online technology is consumer self-protection. This situation explains that users need to have the knowledge and skills for precautions against the use of digital electronic devices. Not only that, users are responsible for maintaining safety and well-being while online. For example, users "installing and updating antivirus software," "installing and updating antispy software," and "shutting down firewalls" are among the security measures. These actions are essential in protecting digital information from being stolen or damaged, giving more adverse effects.

The well-being of the use of technology is closely related to ensuring the ergonomic use of digital tools. Consumers who use digital technology healthily also tend to maintain their physical well-being when using computers and digital devices. For example, use an adjustable chair when using a computer to ensure the focus of the eyes is parallel to the computer screen and is at the appropriate distance. This act is known as 
safe ergonomic behavior [31], reducing the risk of developing long-lasting eyes, poor posture, pain, numbness and other nerve-related disorders caused by computer use.

Online wellbeing and health are identified as physically and psychologically wellbeing in the world of digital technology. Health and wellbeing are linked to the fact that digital people live in virtual and physical spaces. For that kind of reason, the necessary skills of digital competence are not sufficient. Human beings also need a set of behaviors, skills, values and understanding that make them quite aware of challenges regarding health and wellbeing. A digitally developed world, wellness and also wellbeing means being aware of risks and problems that may affect fellow human-being, including, but not limited to, online addiction, ergonomics and posture, and the excessive overuse digital mobile platforms.

According to Ribble [12], students need to be aware of the physical dangers of inherent while using digital technology. A study conducted by researchers at Boston University in 2011 about laptop use and discomfort levels stated that more than $50 \%$ of university students said they already experience pain attributed to the computer. Meanwhile, one in seven said they experience pain after working on a computer for just one hour. Thus, according to Ribble [12], students should be aware of the inherent physical dangers of using technology. Digital technology is impacting change in the development of human life more globally. Nevertheless, insensitivity to being a responsible and ethical user of technology needs to be taken seriously. The prudent use of electronic digital technology needs to be emphasized to benefit human beings and the next generation. Thus, digital citizenship skills such as online learning skills, online security, and digital technology's well-being are seen as a sustainable combination. By studying the level of students' skills based on these three aspects, researchers can assess students' ability as responsible and ethical digital citizens.

Based on a study by Hui and Campbell [32], the emphasis on ethical aspects is related to attitudes or behaviors in the online environment. The study of digital citizenship is significant to implement because most teenagers in this century do not understand the formation of explicit digital norms and culture. This situation happened because the things that teenagers learn from digital media sites are considered a culture that forces them to agree to participate in various current activities or trends regardless of personal safety factors while online. The internet as a world without borders is present with good benefits and invites various risks to the current generation. Digital citizenship skills need to be developed from the very beginning. This study examines the level of digital citizenship skills of Universiti Pendidikan Sultan Idris's undergraduate in online learning, online safety, and online well-being.

\section{RESEARCH METHOD}

This research focused on a quantitative study using survey design. Selection of survey methods was because this study used a questionnaire instrument to assess respondents' level of digital citizenship skills. This method has advantages because it can be administered directly to the respondents [33]-[35] besides, the use of questionnaires provides robust data based on the skills acquired by the respondents. The study sample involved 1000 undergraduates' students. They were asked to respond to the questionnaire to evaluate the digital citizenship skills that comprise online well-being, online learning, and online security. This study was conducted at the Universiti Pendidikan Sultan Idris in Tanjong Malim, Perak, Malaysia. The selection of this study's location is because this university is an educational institution that produces credible human capital. This study involved 17,893 student population from nine faculties. Through simple random strata sampling, 1000 students were selected as the study sample as shown in Table 1.

This study used a questionnaire as a research instrument, consisting of two parts, namely part A and part B are presented in Table 2. Part A contains the respondents' demographic information, while Section B covers information on the study variable, which is digital citizenship skills.

Table 1. Population and sample

\begin{tabular}{|c|c|c|}
\hline Faculty & Population & Sample \\
\hline Faculty of Languages and Communication & 2,756 & 154 \\
\hline Faculty of Human Development & 2,067 & 116 \\
\hline Faculty of Human Sciences & 2,703 & 151 \\
\hline Faculty of Arts, Computers and Creative Industries & 2,736 & 153 \\
\hline Faculty of Science and Mathematics & 2,433 & 136 \\
\hline Faculty of Sports Science and Coaching & 1,502 & 84 \\
\hline Faculty of Technical and Vocational & 1,040 & 58 \\
\hline Faculty of Music and Performing Arts & 717 & 40 \\
\hline Faculty of Management and Economics & 1,939 & 108 \\
\hline Total & 17,893 & 1000 \\
\hline
\end{tabular}

Int J Eval \& Res Educ, Vol. 10, No. 3, September 2021: 835 - 844 
Table 2. Respondent questionnaire information

\begin{tabular}{lllc}
\hline Part & \multicolumn{1}{c}{ Details } & \multicolumn{1}{c}{ Construct } & Number of items \\
\hline A & Background of respondent & Gender & 2 \\
& & Races & 6 \\
& & Faculty & 9 \\
& & Types of digital use & 4 \\
& & Purpose of using digital tools & 6 \\
& & Hours of digital device usage & 6 \\
B & \multirow{2}{*}{ Digital citizenship literacy skills } & Online wellbeing & 11 \\
& & Online learning & 12 \\
& & Online security & 8 \\
\hline
\end{tabular}

\subsection{Instrument reliability}

The literacy skills element's reliability with Cronbach's Alpha value, which measures the variables' internal consistency and reliability are presented in Table 3. According to Babbie [36], Cronbach's Alpha value is classified based on a reliability index classification where the $0.90-1.00$ value is very high, $0.70-0.89$ is high, 0.30-0.69 is moderate, and 0.00-0.30 is low. The analysis results showed that the Cronbach's Alpha value was at a high level of classification, which exceeded 0.80 . This study instrument has high reliability, according to Babbie's classification [36].

Table 3. Instrument reliability

\begin{tabular}{lcc}
\hline \multicolumn{1}{c}{ Variable construct } & No. Item & Cronbach's alpha \\
\hline Digital citizenship skills & 31 & .885 \\
Online wellbeing & 11 & .916 \\
Online learning & 12 & .897 \\
Online security & 8 & .874 \\
\hline
\end{tabular}

The instrument was validated by the content experts among academics. Content validity refers to the extent to which the items on a test are representative of the entire domain the analysis seeks to measure, and this assessment needs to be performed by an appraisal expert [37]. The three experts evaluate the instrument based on characteristics such as: The content of the study instrument is appropriate; The division of ideas into sub-titles is appropriate; The meaning of each study item is exact; The language used is easy to understand; The writing size is appropriate and easy to understand; The instructions given are clear; The distance between words is appropriate; The Likert scale indicator is precise; There are no spelling errors; The objectives of the instrument are clearly stated.

The instrument evaluator consists of two experts in technology education and one from the field of moral education as shown in Table 4. After the item corrected according to the expert recommendation, a pilot study was conducted to see the reliability of the item.

Table 4. Questionnaire experts' field

\begin{tabular}{cccc}
\hline No & Expert & Field & Institution \\
\hline 1 & Expert 1 & Moral education & Universiti Pendidikan Sultan Idris \\
2 & Expert 2 & Technology education & Universiti Pendidikan Sultan Idris \\
3 & Expert 3 & Technology education & Universiti Pendidikan Sultan Idris \\
\hline
\end{tabular}

\section{RESULTS AND DISCUSSION}

\subsection{Respondent background}

Table 5 shows the demographic information of the Universiti Pendidikan Sultan Idris students. A total of 1000 respondents were selected to answer the questionnaire. Female students comprise $68.4 \%$ compared to $31.6 \%$ of male students. The majority of the respondents were Malay $(62.6 \%)$, followed by $14.9 \%$ Bumiputera Sabah, 9.8\% Bumiputera Sarawak, 6.0\% Indian, 5.7\% Chinese, and 1.0\% others. The respondents were selected randomly from nine faculties. $98.7 \%$ of respondents used smartphones as digital devices, followed by the use of laptops $(87.3 \%)$, desktops $(14.9 \%)$, other devices $(9.2 \%)$ and tablets $(9.1)$. Also, the results showed that the use of digital devices for educational purposes was $88.6 \%$ followed by entertainment (82.7\%), communication (79.7\%), expertise $(63.3 \%)$, politics $(20.7 \%)$, and other purposes $(5.6$ $\%$ ). Majority of the respondents spent 8 to 10 hours using digital tools, and only $1.0 \%$ of respondents spent less than 2 hours using digital tools. 
Table 5. Respondent's demography

\begin{tabular}{|c|c|c|c|}
\hline & & $\mathrm{N}$ & $\%$ \\
\hline \multirow{4}{*}{ Gender } & Male & 316 & 31.6 \\
\hline & Female & 684 & 68.4 \\
\hline & Malay & 626 & 62.6 \\
\hline & Indian & 60 & 6.0 \\
\hline \multirow{8}{*}{ Race } & Chinese & 57 & 5.7 \\
\hline & Bumiputera Sabah & 149 & 14.9 \\
\hline & Bumiputera Sarawak & 98 & 9.8 \\
\hline & Others & 10 & 1.0 \\
\hline & Faculty of Languages and Communication & 154 & 15.4 \\
\hline & Faculty of Human Development & 116 & 11.6 \\
\hline & Faculty of Human Sciences & 151 & 15.1 \\
\hline & Faculty of Arts, Computers and Creative Industries & 153 & 15.3 \\
\hline \multirow[t]{7}{*}{ Faculty } & Faculty of Science and Mathematics & 136 & 13.6 \\
\hline & Faculty of Sports Science and Coaching & 84 & 8.5 \\
\hline & Faculty of Technical and Vocational & 58 & 5.8 \\
\hline & Faculty of Music and Performing Arts & 40 & 4.0 \\
\hline & Faculty of Management and Economics & 108 & 10.8 \\
\hline & Smartphone & 988 & 98.7 \\
\hline & Tablet & 91 & 9.1 \\
\hline \multirow[t]{5}{*}{ Type of digital tools } & Laptop & 873 & 87.3 \\
\hline & Desktop & 149 & 14.9 \\
\hline & Others & 92 & 9.2 \\
\hline & Education & 886 & 88.6 \\
\hline & Politic & 207 & 20.7 \\
\hline \multirow{6}{*}{ Digital tools purpose } & Entertainment & 827 & 82.7 \\
\hline & Expertise & 363 & 36.3 \\
\hline & Communication & 797 & 79.7 \\
\hline & Others & 56 & 5.6 \\
\hline & $0<2$ & 10 & 1.0 \\
\hline & $2-4$ & 61 & 6.1 \\
\hline \multirow{4}{*}{ Daily internet usage hours } & $4-6$ & 195 & 19.5 \\
\hline & $6-8$ & 247 & 24.7 \\
\hline & $8-10$ & 253 & 25.3 \\
\hline & $>10$ & 234 & 23.4 \\
\hline
\end{tabular}

$\mathrm{N}=1000$ sample

\subsection{Digital citizenship skills level}

The digital citizenship skills level is analyzed through three sub-variables; online wellbeing, online learning and online security. To facilitate the interpretation of the levels of each variable, this study divides the levels into three levels (low, moderate, and high) [38]. Cut off point is used to determine the digital citizenship skills level is shown in Table 6, while the levels of digital citizenship skills are presented in Table 7.

Table 7 shows that the level of skills of students' digital citizens is at a high level with a mean value of 4.06 with a standard deviation of .468 . The skill variables were divided into three sub-variables, specifically online well-being skills $(\mathrm{M}=3.46, \mathrm{SD}=.997)$ at the moderate level, meanwhile, online learning skills ( $\mathrm{M}=4.37, \mathrm{SD}=.456)$, and online safety skills $(\mathrm{M}=4.43, \mathrm{SD}=.547)$ at the high level.

Table 6. Cut-off point for each construct

\begin{tabular}{cc}
\hline Scale & Level \\
\hline $1.00-2.33$ & Low \\
$2.34-3.66$ & Moderate \\
$3.67-5.00$ & High \\
\hline
\end{tabular}

Table 7. The construct level of digital citizenship skills

\begin{tabular}{lccccccccc}
\hline \multicolumn{1}{c}{ Variables } & \multicolumn{2}{c}{ Low } & \multicolumn{2}{c}{ Moderate } & \multicolumn{2}{c}{ High } & \multirow{2}{*}{ Mean } & \multirow{2}{*}{ SD } & \multirow{2}{*}{ level } \\
\hline Digital citizenship skills & 0 & 0 & 197 & 19.7 & 803 & 80.3 & 4.06 & .468 & High \\
Online wellbeing & 157 & 15.7 & 366 & 36.6 & 477 & 47.7 & 3.46 & .997 & Moderate \\
Online learning & 0 & 0 & 57 & 5.7 & 943 & 94.3 & 4.37 & .456 & High \\
Online security & 5 & .5 & 64 & 6.4 & 931 & 93.1 & 4.43 & .547 & High \\
\hline
\end{tabular}


Table 8 shows the mean scores for online well-being skills of digital citizens among students. The entire item for the digital citizen online wellbeing skills variable at the moderate level except for the K26 item "I use the internet for a long time to achieve self-satisfaction" is at a high level $(\mathrm{M}=3.92, \mathrm{SD}=1.577)$. Students use the internet for an extended period to achieve self-satisfaction by surfing the internet. This act has indirectly had other adverse effects. Which is referring to items K30, K31, K32, and K33 shows that students are often tired of using digital devices for an extended period. Their vision had been affected, headaches, and pain in the shoulders and neck due to body posture errors when facing a computer screen. This explains why the level of online well-being skills of students is at a moderate level. It is vital for students need to know the correct ways to use technology without compromising physical and mental health.

Table 8. Digital citizen skills level in online wellbeing

\begin{tabular}{|c|c|c|c|}
\hline & Item & Mean & $\begin{array}{l}\text { Standard } \\
\text { deviation }\end{array}$ \\
\hline K15 & I reported incidents of cyberbullying, intimidation, and identity theft against the authorities. & 3.33 & 1.508 \\
\hline K16 & I report identity theft that occurred against the authorities. & 3.36 & 1.526 \\
\hline $\mathrm{K} 25$ & I once bought or downloaded pirated digital materials. & 2.92 & 1.577 \\
\hline K26 & I use the internet for a long time to achieve self-satisfaction. & 3.92 & 1.074 \\
\hline $\mathrm{K} 27$ & I often feel restless/depressed/angry when there is no internet. & 3.34 & 1.268 \\
\hline $\mathrm{K} 28$ & I use the internet to escape from unwanted problems and feelings such as helplessness and anxiety. & 3.15 & 1.501 \\
\hline K29 & I use the internet as a way to escape emotional problems such as depression. & 3.09 & 1.488 \\
\hline K30 & I feel tired when using digital tools for a long time. & 3.70 & 1.200 \\
\hline K31 & My vision becomes blurred when using digital tools for long periods. & 3.74 & 1.219 \\
\hline K32 & I once felt a headache when looking at the screen for a long time. & 3.69 & 1.215 \\
\hline K33 & I once felt pain in the shoulders and neck due to the incorrect posture position of the screen. & 3.85 & 1.173 \\
\hline
\end{tabular}

Table 9 shows the overall items for the digital citizenship of online learning skills. A total of 12 items are at a high level between the mean score of 4.09 to 4.57 . These findings prove that skills in online learning have now become an essential element in digital citizenship education. Online learning skills enhance students' skills and productivity more effectively. Students use digital devices as part of teaching and learning tools. Students are using the internet as a competent resource, exploring online learning methods, and even using social media applications for information sharing. This statement refers to the items for K1, $\mathrm{K} 2$, K5, and $\mathrm{K} 7$. Items for $\mathrm{K} 3, \mathrm{~K} 4, \mathrm{~K} 5$, and $\mathrm{K} 10$ in online learning skills discuss that student have a high level of understanding digital terms, verifying online resources' authenticity, and identifying threats when using the internet. Table 10 shows the level of online security skills of digital citizens among students. Overall, the items for the online security skills showed a high level above the mean score of 3.67.

Table 9. Digital citizenship skills of online learning

\begin{tabular}{clcc}
\hline & \multicolumn{1}{c}{ Item } & Mean & Standard deviation \\
\hline K1 & I use digital tools as teaching and learning tool. & 4.57 & .553 \\
K2 & I use the internet as a more competent source of learning. & 4.50 & .568 \\
K3 & I am good at digital terms; browser, search engine, download, email, and more. & 4.35 & .658 \\
K4 & I evaluate the validity of the material source obtained online. & 4.35 & .631 \\
K5 & I explore online learning methods. & 4.38 & .670 \\
K6 & I know how to sign up a social media service application account by myself. & 4.47 & .608 \\
K7 & I use social media service applications for information sharing purposes. & 4.37 & .679 \\
K8 & I use digital technology as a medium to provide insights. & 4.32 & .705 \\
K9 & I use digital tools to share ideas and write with others & 4.29 & .738 \\
K10 & I quickly identify the threats of using the internet (Examples; identity theft, online fraud). & 4.09 & .822 \\
K11 & I follow the development of current issues through the medium of digital technology. & 4.40 & .625 \\
K12 & I disseminate information on humanitarian aid needed on social media sites. & 4.34 & .697 \\
\hline
\end{tabular}

Table 10. Digital citizenship skills of online security

\begin{tabular}{llcc}
\hline & Item & Mean & Standard deviation \\
\hline K13 & I will make sure the money transaction had done on a secure trading site. & 4.49 & .650 \\
K14 & I make sure not to make purchases from suspicious business sites. & 4.44 & .749 \\
K17 & I set personal settings on my digital gadget so that it is not easily accessible to outsiders. & 4.45 & .763 \\
K20 & I have storage of information in Cloud Storage (Google Drive, Dropbox, and others). & 4.41 & .763 \\
K21 & I logged out after using the internet banking line. & 4.50 & .713 \\
K22 & I know that conducting transactions online has the risk of being scammed. & 4.47 & .715 \\
K23 & I make price comparisons for each digital trading site. & 4.41 & .714 \\
K24 & I once bought or downloaded pirated digital materials. & 4.30 & .914 \\
\hline
\end{tabular}


Students' online learning skills and online security skills show at a high level compared to online well-being at a moderate level. Skills on online well-being are seen to be moderate as students consider not overemphasizing the balance of digital use. Many consider online well-being skills unimportant. Without realizing it, the use of technologically profound, physical, emotional, and moral aspects is a healthy combination of a good digital citizen's formation. This study's finding has significant implications for digital citizenship education, particularly in every level of education. Also, digital citizenship's well-being indirectly teaches consumers that the needs to respect, educates, and protect themselves and other digital users are physically and emotionally important. Therefore, the misuse of digital tools, such as excessive, uncontrolled use, negatively impacted digital users themselves. The emphasis on digital citizenship education, especially in terms of online learning skills, prove that technology, as a learning medium, has become ingrained in the education system today. Online learning is one aspect that makes digital users a digital citizen who has digital access without any restrictions. Skills in the prudent use of information communication technology need to be addressed in a borderless cyber world. Technology users need to emphasize the importance of online security so that digital technology users' actions do not invite adverse effects on society. Thus, awareness of the importance of digital technology; should be accompanied by online security of use. Online security needs to be emphasized because today's digital users are too daring to criticize without a check motion. Users need to be smart to explore and find information because there is too much dissemination of information that cannot be verified.

The importance of digital citizenship education especially in skills learning, create a youth identity in the digital environment and form an ethical digital community [23]. A fundamental foundation in the study of digital citizenship among adolescents begins with understanding the changing digital environment and the level of developmental characteristics of adolescents [39]. Digital citizenship skills indirectly form a relationship in a digital technology environment; identity building and self-awareness are known as psychosocial desires. Experience in the use of technology indirectly further enhances digital users' skills at a more encouraging level. The digital citizenship education framework should cover various aspects of human relationships and social contexts based on digital literacy and ethical dimensions [40], [41].

Discussion on concepts that associated with digital citizenship which are digital literacy, media literacy, 21st century skill as well as digital competence is focusing on helping young people understand the values and norms around responsible and appropriate use of digital technologies. These concepts are typically associated with frameworks and accompanying learning materials that aim to help individuals address the challenges and recognize the opportunities correspond with digital world. Fuller [42] mention that ISTE added that educators train youth's digital citizenship by, for example, teaching young people how to understand and apply legal concepts to the content they share, having skills to manage their online security, and assess the credibility of information online [42].

Mossberger, Tolbert, and McNeal [43, p.1], propose a digital citizen are those "who use the internet regularly and effectively that is, on a daily basis." "Effective" internet use not only implies daily Internet use, but also a technical ability to use digital technologies and possessing the skills to find, understand, analyze, and use information in the digital circumstance. This result suggest that students already equipped with what so called digital citizenship values and skills and have abilities to embrace the process of practicing their digital citizenship knowledge and skills in the digital world. Nonetheless as much as digital technology and media literacy started to become more common in schools, what does digital citizenship education look like in the classroom today? How schools incorporated digital citizenship education? Are teachers engaged fully in preparing their class with digital citizenship knowledge, values and skills? What does digital citizenship education look like in classrooms in other parts of the world?

In 2016 UNESCO undertook a review of Member States' national digital citizenship policies for pre-primary, primary, and secondary schools as part of their "Fostering Digital Citizenship through Safe, Effective and Responsible Use of ICT. The study revealed that a vast majority (80\%) has national programs, policies, and resources for secondary schools that aim to cultivate basic skills related to digital technologies. However, $55 \%$ of the state member have implemented policies for secondary schools geared towards promoting skills around more participatory and creative ways of engaging with the digital world and only about half of member states have implemented policies around promoting the responsible and safe use of digital technologies. Overall, it can be concluded that nation around the world are trying to engage with digital citizenship but not fully implemented the so-called digital citizenship education and creating digital citizens in school.

As suggested by UNESCO as cited in Cortesi, et al. [44], findings, policy recommendations that engaged digital citizenship education that balance the opportunities and risks associated with digital world. Children and young people should be encouraging to be ready and involved in digital technologies in creative and participatory ways. Malaysia has no exception. Policy makers, educators and teachers should be ready to be part of digital citizenship education. Digital citizenship education should be implemented on school 
children and future teachers who already equipped with such knowledge and skills should be provided with opportunities to educate young children with digital citizenship education.

\section{CONCLUSION}

The study results on digital citizenship skills are useful information to be studied by academia in evaluating Malaysia's education system. The study results also show that the level of skills of undergraduate students is at a high level. The university's efforts, teaching staff, and the ministry in promoting the use of digital technology as a whole are very satisfactory. Students' readiness to become digital citizens who care about well-being, learning, and security indirectly proves that today's students have a high level of awareness in using technology appropriately. Formulating policies and practices to develop digital citizenship skills for national development can be built from this study's results. Policies related to digital citizenship should be formulated in accordance with the practice of digital citizenship especially starting based on education. The policy is built by introducing digital citizenship norms and principles and further enhancing knowledge, skills, and awareness of digital citizenship issues.

Therefore, this study opens an opportunity for other researchers to continue study the digital community's skills in different demographics. It is hoped that there will be research in the future on digital citizenship skills based on other factors. Students' importance to become good digital citizens and use technology responsibly is necessary to continuously increase the level of knowledge, skills, and awareness. The effectiveness of being a proactive digital citizen can be achieved through digital citizenship education. Relevant literacy and practicality are needed to cultivate digital users' confidence and positive attitude towards technology. This study opens up opportunities for other researchers to broaden studies on the digital citizenship literacy and skills in different demographics. Future research from different paradigm and methodology should be done to grasp opportunities and challenges surroundings framework of digital citizenship and digital citizenship education. Policy makers, stakeholders, educators in Malaysia in particularly should be partnership in education digital citizens. Young people are not digital citizens to be, they are the digital citizens.

\section{ACKNOWLEDGEMENTS}

This study had conducted with the help of a Fundamental Research Grant (FRGS 2019-0026-10602). Thanks to the Universiti Pendidikan Sultan Idris, Malaysia, for the research funds and to the respondents who participated in this research study.

\section{REFERENCES}

[1] ISTE, "ISTE standards for students," International Society for Technology in Education, 2016. [Online]. Available: https://www.iste.org/standards/iste-standards-for-students. (accessed: Jan. 25, 2020).

[2] C. James, E. Weinstein, and K. Mendoza, Teaching Digital Citizens in Today's World: Research and Insights Behind the Common Sense K-12 Digital Citizenship Curriculum. San Francisco, CA: Common Sense Media, 2019.

[3] A. Collier, "A definition of digital literacy \& citizenship," Net Family News, 2009. [Online]. Available: https://www.netfamilynews.org/a-definition-of-digital-literacy-citizenship.

[4] A. Lenhart, M. Madden, A. Smith, K. Purcell, and K. Zickuhr, "Teens, kindness and cruelty on social network sites," Pew Research Center, pp. 1-86, Nov. 2011.

[5] J. R. Schermerhorn, Management, 8th Edition. United States: John Wiley \& Sons, 2005.

[6] UK Commission for Employment and Skills (UKCES), The supply and demand for high-level STEM skills. Wathupon-Dearne, England: UKCES, 2011. [Online]. Available: http://hdl.voced.edu.au/10707/193537.

[7] Digital Technologies Hub, "Digital Citizenship," Education Services Australia, 2020. [Online]. Available: https://www.digitaltechnologieshub.edu.au/teachers/topics/digital-citizenship. (accessed: Jan. 25, 2020).

[8] R. Susanty, Z. Yunos, M. Ahmad, and N. Razali, "Instilling Digital Citizenship Skills Through Education: A Malaysian Perspective," in European Conference on Cyber Warfare and Security, 2019, pp. 819-827.

[9] A. G. Logan, "Digital Citizenship in 21st Century Education," Thesis, Dominican University of California, 2016.

[10] C. H. Manzuoli, A. V. Sánchez, and E. D. Bedoya, "Digital Citizenship: A Theoretical Review of the Concept and Trends," Turkish Online J. Educ. Technol. - TOJET, vol. 18, no. 2, pp. 10-18, 2019.

[11] A. N. Aslamiah, "Digital Citizens: Adab dan Tanggungjawab," in Dimensi Koop Bil. 47: Impak Amalan Kepimpinan 4E Terhadap Koperasi. Institut Koperasi Malaysia, 2015. [Online]. Available: https://ikkm.edu.my/images/dokumen/penerbitan/demensi/demensi-koop-47/47-2.pdf.

[12] M. Ribble, Digital Citizenship in Schools: Nine Elements All Students Should Know, 3rd Edition. Washington DC: International Society for Technology in Education, 2015.

[13] E. M. Selkie, R. Kota, Y. F. Chan, and M. Moreno, "Cyberbullying, depression, and problem alcohol use in female college students: a multisite study," Cyberpsychology, Behav. Soc. Netw., vol. 18, no. 2, pp. 79-86, 2015. 
[14] R. Donegan, "Bullying and cyberbullying: History, statistics, law, prevention and analysis," Elon J. Undergrad. Res. Commun., vol. 31, no. 3, pp. 33-42, 2012.

[15] A. B. Perkins, J. V. Becker, M. Tehee, and E. Mackelprang, "Sexting behaviors among college students: cause for concern?" Int. J. Sex. Heal., vol. 26, no. 2, pp. 79-92, 2014.

[16] R. D'antona, M. Kevorkian, and A. Russom, "Sexting, texting, cyberbullying and keeping youth safe online," $J$. Soc. Sci., vol. 6, no. 4, pp. 523-528, 2010.

[17] C. B. Fried, "In-class laptop use and its effects on student learning," Comput. Educ, vol. 50, no. 3, pp. 906-914, 2018.

[18] R. William, "Internet plagiarism rising in schools," The Guardian Online, 2010. [Online]. Available: https://www.theguardian.com/education/2010/jun/20/internet-plagiarism-rising-in-schools.

[19] S. Hudani, "The importance of teaching digital citizenship," FreeTech4Teachers.com by Byrne Instructional Media, 2014. [Online]. Available: https://www.freetech4teachers.com/2014/05/the-importance-of-teachingdigital.html.

[20] M. S. Nordin, et al., "Psychometric properties of a digital citizenship questionnaire," Int. Educ. Stud, vol. 9, no. 3, pp. 71-80, 2016.

[21] M. Ribble, G. Bailey, and T. Ross, "Digital Citizenship: Addressing Appropriate Technology Behavior," Learn. Lead. with Technol, vol. 32, no. 1, p. 6, 2004.

[22] S. Atep and R. Dewi, "Literasi digital abad 21 bagi mahasiswa PGSD : apa , mengapa, dan bagaimana," Curr. Res. Educ. Conf. Ser. J, vol. 1, no. 1, pp. 1-7, 2019.

[23] M. Kim and D. Choi, "Development of Youth Digital Citizenship Scale and Implication for Educational Setting," J. Educ. Technol. Soc, vol. 21, no. 1, pp. 155-171, 2018

[24] A. Yacine and C. Chien, "Digital Citizenship: Innovations in Education, Practice, and Pedagogy," J. Educ. Technol. Soc, vol. 21, no. 1, pp. 152-154, 2018.

[25] K. Mossberger, C. Tolbert, and A. Hamilton, "Measuring Digital Citizenship: Mobile Access and Broadband Measuring Digital Citizenship : Mobile Access and Broadband," Int. J. Commun, vol. 6, pp. 2492-2528, 2012.

[26] M. Elcicek, H. Erdemci, and H. Karal, "Examining the relationship between the levels of Digital Citizenship and Social Presence for the graduate students having online education," Turkish Online J. Distance Educ, vol. 19, no. 1, pp. 203-214, 2018

[27] C. Greenhow, B. Robelia, and J. E. Hughes, "Learning, teaching, and scholarship in a digital age Web 2.0 and classroom research: What path should we take now?" Educ. Res., vol. 38, no. 4, pp. 246-259, 2009.

[28] W. L. Bennett, "Changing citizenship in the digital age," Foundation series on digital media and learning. Civic life online: Learning how digital media can engage youth. MIT Press, 2008, pp. 1-24.

[29] J. Ohler, "Digital citizenship means character education for the digital age," Kappa Delta Pi Rec., vol. 47, pp. 25-27, 2011.

[30] Maryland State Board of Education, Science, Technology, Engineering And Mathematics (STEM) Education. Baltimore: Maryland State Board of Education, 2012.

[31] R. Hollandsworth, L. Dowdy, and J. Donovan, "Digital citizenship in K-12: It takes a village," TechTrends, vol. 55 , no. 4, pp. 37-47, 2011.

[32] B. Hui and R. Campbell, "Discrepancy between Learning and Practicing Digital Citizenship," J. Acad. Ethics, vol. 16, no. 2, pp. 117-131, 2018 .

[33] R. B. Burns, Introduction to research methods, 4th Ed. London, UK: SAGE Publications, 2000.

[34] M. Sabitha, Penyelidikan Sains Sosial: Pendekatan Pragmatik. Batu Caves, Selangor: Edusystem Sdn. Bhd, 2006.

[35] Z. Awang, Research Methodology for Business and Social Science. Shah Alam: University Publication Centre, UiTM, 2010.

[36] E. Babbie, The Practice of Social Research. Belmont, California: Thomsom Wadsworth, 1992.

[37] A. Bhattacherjee, Social science research: Principles, methods and practices. Global Text Project, 2012.

[38] K. Landell, Management by Menu. London: Wiley dan Sons Inc, 1997.

[39] M. Israelashvili, T. Kim, and G. Bukobza, "Adolescents' over-use of the cyber world-Internet addiction or identity exploration?” J. Adolesc., vol. 35, no. 2, pp. 417-424, 2012.

[40] L. M. Jones and K. J. Mitchell, "Defining and measuring youth digital citizenship," New media Soc., vol. 18, no. 9, pp. 2063-2079, 2016

[41] A. Nosko and E. Wood, "Learning in the digital age with SNSs," in Creating a profile Social media tools and platforms in learning environments. Berlin, Germany: Springer, 2011, pp. 399-418.

[42] M. T. Fuller, "ISTE standards for students, digital learners, and online Learning," in Handbook of Research on Digital Learning. IGI Global, 2020, pp. 284-290.

[43] K. Mossberger, C. J. Tolbert, and R. S. McNeal, Digital Citizenship - The Internet, Society \& Participation. MIT Press, 2007.

[44] S. Cortesi, A. Hasse, A. Lombana, S. Kim, and U. Gasser, "Youth and Digital Citizenship+ (Plus): Understanding Skills for a Digital World,” Berkman Klein Center for Internet \& Society, 2020. 